\title{
Frequency and cost of potentially inappropriate prescribing for older adults: a cross-sectional study
}

\author{
Steven G. Morgan PhD, Jordan Hunt MA, Jocelyn Rioux BSc, Jeffery Proulx BSc, Deirdre Weymann MA, \\ Cara Tannenbaum MD MSc
}

\section{Abstract}

Background: Many medications pose greater health risks when prescribed for older adults, compared with available pharmacologic and nonpharmacologic alternatives. We sought to quantify the frequency and cost of potentially inappropriate prescribing for older women and men in Canada.

Methods: Using data for 2013 from the National Prescription Drug Utilization Information System database, which contains prescription claims from publicly financed drug plans in all provinces except for Quebec, we identified the frequency of prescribing and cost of potentially inappropriate medications dispensed to provincial drug plan enrollees aged 65 years or more. Potentially inappropriate prescriptions were defined with the use of the American Geriatrics Society's 2012 version of the Beers Criteria for potentially inappropriate medication use in older adults.

Results: For the 6 provinces with relatively complete data coverage (British Columbia, Alberta, Saskatchewan, Manitoba, Ontario and Prince Edward Island), 37\% of older people filled 1 or more prescription meeting the Beers Criteria. A higher proportion of women (42\%) than men (31\%) filled potentially inappropriate prescriptions. The highest rates of prescribing of potentially inappropriate medications were among women aged 85 or more (47\%). Benzodiazepines and other hypnotics were the leading contributors to the overall frequency of and sex differences in prescribing of potentially inappropriate drugs among older adults. We estimated that $\$ 75$ per older Canadian, or $\$ 419$ million in total, was spent on potentially inappropriate medications outside of hospital settings in 2013.

Interpretation: Prescribing of potentially inappropriate medications for older adults is common and costly in Canada, especially for women. Multipronged and well-coordinated strategies to reduce the use and cost of potentially inappropriate drugs would likely generate significant health system savings while simultaneously generating major benefits to patient health.

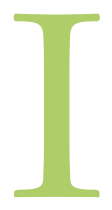
$\mathrm{n}$ caring for older patients, particular attention to prescribing appropriateness is required because many medications pose greater health risks when prescribed for older adults, compared with available The use of such potentially inappropriate medications among older patients is relatively common and can lead to unnecessary hospital admissions and increase the risk of death. ${ }^{5-7}$

Leaders in Canada's medical profession are taking increased action to help physicians and patients choose prescription drug treatments wisely. ${ }^{8}$ Such clinical leadership is a critical step toward promoting more appropriate use of medicines in Canada. However, although medication safety has been identified as a strategic priority of the National Patient Safety Consortium, ${ }^{9}$ Canadian governments have yet to invest in a large-scale, pan-Canadian strategy on prescribing quality.
The scale of required investments may be one of the barriers to implementing a comprehensive strategy for improving the quality of prescribing in Canada. Professional education and academic detailing, public awareness and patient education campaigns, and the development of electronic systems for prescription decision-making, monitoring and feedback all have the potential to contribute to better medicine use in Canada, but all come at considerable cost. ${ }^{10}$ To help inform policy discussions regarding the costs and benefits of

Competing interests: None declared.

This article has been peer reviewed.

Correspondence to: Steven Morgan, steve.morgan@ubc.ca CMAJ Open 2016. DOI:10.9778/cmajo.20150131 
quality-improvement initiatives, we sought to quantify the frequency and cost of prescribing of potentially inappropriate medications for older Canadians.

\section{Methods}

\section{Study design and setting}

This is a cross-sectional study of the frequency and cost of potentially inappropriate prescriptions for older women and men in 9 Canadian provinces. Populations studied included all residents aged 65 years or more. All of these people are covered under Canada's universal public health insurance system for medical and hospital care, which is run by the provinces but held to national standards - including universality, comprehensiveness and accessibility - by way of federal costsharing. Owing to a lack of such national standards for prescription drug coverage in Canada, public drug coverage differs across provinces in eligibility criteria, premiums, deductibles and copayments/coinsurance. ${ }^{11}$

\section{Data sources}

This study draws on data for 2013 from the National Prescription Drug Utilization Information System (NPDUIS) database, housed at the Canadian Institute for Health Information. We used 2013 data because they were the most recent NPDUIS data available for all participating provinces at the time of analysis. The NPDUIS database contains prescription claims from publicly financed drug plans in all provinces except for Quebec. These data cover the dispensing and cost of prescriptions filled by plan enrollees outside of acute care hospitals, which account for about $90 \%$ of the total pharmaceutical market inclusive of hospital purchases. ${ }^{12}$

The NPDUIS database contains records of prescriptions for which at least part of the drug cost was accepted as an eligible cost by the public plan, either for payment by the program or as credit toward the program's deductible (if applicable). The NPDUIS data therefore exclude drugs not covered by provincial drug plans and patients not entitled to or registered for public drug benefits.

\section{Variables}

We identified the frequency and cost of potentially inappropriate prescriptions for beneficiaries aged 65 years or more covered by provincial drug benefit programs using the American Geriatrics Society's 2012 version of the Beers Criteria for potentially inappropriate medication use in older adults. ${ }^{1}$ Drugs in the NPDUIS database were classified with the use of the fifth level of the 2014 version of the World Health Organization's Anatomical Therapeutic Chemical classification system. ${ }^{13}$

We applied methods for implementing the Beers Criteria with Canadian data that were developed and described by the Canadian Institute for Health Information. ${ }^{14}$ Appendix 1 (available at www.cmajopen.ca/content/4/2/E346/suppl/DC1) provides a summary of included medications.

All prescriptions meeting the Beers Criteria based on drug, dosage and duration were identified as potentially inappropriate. That is, some drugs on the Beers list are con- sidered potentially inappropriate only if taken in a certain formulation (for example, chlorpropamide should not be taken if long acting) or if taken in excess of a specific dosage (e.g., reserpine dosages $>0.1 \mathrm{mg} / \mathrm{d}$ ). One exception was insulin, which was not included in this analysis because it is considered potentially inappropriate only if prescribed to be taken on a sliding scale, which is impossible to determine from drug claims data alone.

We measured total costs of prescriptions using relevant fields in the NPDUIS data set, including ingredient cost and dispensing fees. Because most provincial drug plans for older people involve deductibles, coinsurance or copayments paid by enrollees, our cost estimates included public payment for the medicines in addition to payments made by patients. We extrapolated the per-enrollee cost of potentially inappropriate prescriptions among provinces with high NPDUIS data coverage to the national population of people aged 65 or more using Statistics Canada's population estimates by age and sex..$^{15}$

\section{Statistical analyses}

For all medications on the Beers list combined and for the 20 most frequently used drugs on the list, we computed the period prevalence of provincial drug plan enrollees' filling 1 or more potentially inappropriate prescription, by province, sex and age, as well as the total cost of potentially inappropriate prescriptions filled by enrollees, by province, sex and age.

We report results for each province individually. However, to account for potential biases stemming from differences in the proportions of older adults eligible for public drug coverage between provinces (which, in turn, could reflect selection bias associated with public coverage targeted at more vulnerable members of the older population), we also report pooled results for provinces in which at least $85 \%$ of the population aged 65 or more is covered by the NPDUIS database. We refer to these provinces as high-data-coverage provinces with respect to the data used in this study.

There were small differences in the age profile of provincial populations aged 65 years or more and of public drug plan beneficiaries aged 65 or more. To test for bias in provincial reporting rates of potentially inappropriate prescribing, we compared crude and age-standardized results.

We performed all analyses using SAS version 9.2 and MS Excel 2013. This study was approved by the University of British Columbia's Behavioural Research Ethics Board.

\section{Results}

Table 1 shows the proportions of provincial drug plan enrollees aged 65 or more who filled at least 1 potentially inappropriate prescription in 2013. Proportions were highest in the provinces with more limited NPDUIS data coverage (New Brunswick, Nova Scotia, and Newfoundland and Labrador). Age standardization changed province-specific measures of overall rates of potentially inappropriate prescriptions by less than one-third of 1 percentage point (data not shown). In the 6 high-data-coverage provinces, $37.2 \%$ of 


\begin{tabular}{|c|c|c|c|c|c|c|c|c|c|c|}
\hline \multirow[b]{3}{*}{ Province } & \multirow{3}{*}{$\begin{array}{c}\text { Population (\%) } \\
\text { aged } \geq 65 \mathrm{yr} \\
\text { covered by } \\
\text { NPDUIS database }\end{array}$} & \multicolumn{9}{|c|}{ Age, yr; no. (\%) of enrollees } \\
\hline & & \multicolumn{4}{|c|}{ Women } & \multicolumn{4}{|c|}{ Men } & \multirow[b]{2}{*}{ Overall } \\
\hline & & $65-74$ & $75-84$ & $\geq 85$ & All ages & $65-74$ & $75-84$ & $\geq 85$ & All ages & \\
\hline British Columbia & $\begin{array}{c}769993 \\
(89.0)\end{array}$ & $\begin{array}{c}89636 \\
(41.5)\end{array}$ & $\begin{array}{c}57288 \\
(44.6)\end{array}$ & $\begin{array}{l}34735 \\
(50.1)\end{array}$ & $\begin{array}{c}181659 \\
(43.9)\end{array}$ & $\begin{array}{l}58678 \\
(28.8)\end{array}$ & $\begin{array}{l}39299 \\
(34.5)\end{array}$ & $\begin{array}{c}16049 \\
(41.2)\end{array}$ & $\begin{array}{c}114026 \\
(32.0)\end{array}$ & $\begin{array}{c}295685 \\
(38.4)\end{array}$ \\
\hline Alberta & $\begin{array}{c}411322 \\
(91.7)\end{array}$ & $\begin{array}{c}54514 \\
(46.5)\end{array}$ & $\begin{array}{c}34388 \\
(47.6)\end{array}$ & $\begin{array}{l}16304 \\
(47.0)\end{array}$ & $\begin{array}{c}105206 \\
(46.9)\end{array}$ & $\begin{array}{l}33675 \\
(31.5)\end{array}$ & $\begin{array}{l}21163 \\
(35.0)\end{array}$ & $\begin{array}{l}7267 \\
(37.0)\end{array}$ & $\begin{array}{c}62105 \\
(33.2)\end{array}$ & $\begin{array}{c}167311 \\
(40.7)\end{array}$ \\
\hline Saskatchewan & $\begin{array}{c}149505 \\
(93.5) \\
\end{array}$ & $\begin{array}{c}14672 \\
(39.4)\end{array}$ & $\begin{array}{l}11764 \\
(42.8)\end{array}$ & $\begin{array}{l}8762 \\
(46.9)\end{array}$ & $\begin{array}{c}35198 \\
(42.2)\end{array}$ & $\begin{array}{l}9455 \\
(27.0)\end{array}$ & $\begin{array}{l}7166 \\
(32.5)\end{array}$ & $\begin{array}{l}3246 \\
(35.9)\end{array}$ & $\begin{array}{l}19867 \\
(30.1)\end{array}$ & $\begin{array}{l}55065 \\
(36.8)\end{array}$ \\
\hline Manitoba & $\begin{array}{c}171195 \\
(93.8)\end{array}$ & $\begin{array}{l}19942 \\
(43.3)\end{array}$ & $\begin{array}{l}13606 \\
(44.8)\end{array}$ & $\begin{array}{l}9209 \\
(46.3)\end{array}$ & $\begin{array}{r}42757 \\
(44.4)\end{array}$ & $\begin{array}{l}12905 \\
(30.8)\end{array}$ & $\begin{array}{l}8353 \\
(35.0)\end{array}$ & $\begin{array}{l}3501 \\
(38.1)\end{array}$ & $\begin{array}{c}24759 \\
(33.0)\end{array}$ & $\begin{array}{l}67516 \\
(39.4)\end{array}$ \\
\hline Ontario & $\begin{array}{c}1971856 \\
(95.9)\end{array}$ & $\begin{array}{c}200391 \\
(36.7)\end{array}$ & $\begin{array}{c}152241 \\
(43.0)\end{array}$ & $\begin{array}{c}89780 \\
(46.1)\end{array}$ & $\begin{array}{c}442412 \\
(40.4)\end{array}$ & $\begin{array}{c}128933 \\
(26.2)\end{array}$ & $\begin{array}{l}96492 \\
(33.8)\end{array}$ & $\begin{array}{l}39125 \\
(38.9)\end{array}$ & $\begin{array}{c}264550 \\
(30.2)\end{array}$ & $\begin{array}{c}706962 \\
(35.8)\end{array}$ \\
\hline New Brunswick & $\begin{array}{c}73482 \\
(55.2)\end{array}$ & $\begin{array}{l}10650 \\
(55.3)\end{array}$ & $\begin{array}{l}8238 \\
(57.3)\end{array}$ & $\begin{array}{l}5969 \\
(61.0)\end{array}$ & $\begin{array}{c}24857 \\
(57.2)\end{array}$ & $\begin{array}{l}6591 \\
(40.6)\end{array}$ & $\begin{array}{l}4689 \\
(44.6)\end{array}$ & $\begin{array}{l}1690 \\
(50.9)\end{array}$ & $\begin{array}{c}12970 \\
(43.1)\end{array}$ & $\begin{array}{c}37827 \\
(51.5)\end{array}$ \\
\hline Nova Scotia & $\begin{array}{c}112780 \\
(67.5)\end{array}$ & $\begin{array}{c}15000 \\
(47.0)\end{array}$ & $\begin{array}{c}10303 \\
(49.0)\end{array}$ & $\begin{array}{l}6559 \\
(49.7)\end{array}$ & $\begin{array}{c}31862 \\
(48.2)\end{array}$ & $\begin{array}{c}10039 \\
(37.3)\end{array}$ & $\begin{array}{l}6539 \\
(42.8)\end{array}$ & $\begin{array}{l}2013 \\
(45.3)\end{array}$ & $\begin{array}{r}18591 \\
(39.9)\end{array}$ & $\begin{array}{l}50453 \\
(44.7)\end{array}$ \\
\hline $\begin{array}{l}\text { Prince Edward } \\
\text { Island }\end{array}$ & $\begin{array}{c}23051 \\
(91.8)\end{array}$ & $\begin{array}{l}2208 \\
(33.6)\end{array}$ & $\begin{array}{l}1393 \\
(34.6)\end{array}$ & $\begin{array}{c}784 \\
(36.8)\end{array}$ & $\begin{array}{l}4385 \\
(34.5)\end{array}$ & $\begin{array}{l}1324 \\
(21.5)\end{array}$ & $\begin{array}{c}813 \\
(25.0)\end{array}$ & $\begin{array}{c}199 \\
(21.9)\end{array}$ & $\begin{array}{l}2336 \\
(22.6)\end{array}$ & $\begin{array}{l}6721 \\
(29.2)\end{array}$ \\
\hline $\begin{array}{l}\text { Newfoundland } \\
\text { and Labrador }\end{array}$ & $\begin{array}{l}49310 \\
(54.9)\end{array}$ & $\begin{array}{l}7658 \\
(56.0)\end{array}$ & $\begin{array}{l}5787 \\
(58.0)\end{array}$ & $\begin{array}{l}3153 \\
(60.1)\end{array}$ & $\begin{array}{l}16598 \\
(57.4)\end{array}$ & $\begin{array}{l}5383 \\
(48.5)\end{array}$ & $\begin{array}{l}3762 \\
(51.8)\end{array}$ & $\begin{array}{l}1097 \\
(53.5)\end{array}$ & $\begin{array}{l}10242 \\
(50.2)\end{array}$ & $\begin{array}{l}26840 \\
(54.4)\end{array}$ \\
\hline $\begin{array}{l}\text { All high-data- } \\
\text { coverage } \\
\text { provinces† }\end{array}$ & $\begin{array}{c}3496922 \\
(92.6)\end{array}$ & $\begin{array}{c}381363 \\
(39.4)\end{array}$ & $\begin{array}{c}270680 \\
(43.9)\end{array}$ & $\begin{array}{c}159574 \\
(47.0)\end{array}$ & $\begin{array}{c}811617 \\
(42.2)\end{array}$ & $\begin{array}{c}244970 \\
(27.7)\end{array}$ & $\begin{array}{c}173286 \\
(34.1)\end{array}$ & $\begin{array}{l}69387 \\
(38.9)\end{array}$ & $\begin{array}{c}487643 \\
(31.0)\end{array}$ & $\begin{array}{c}1299260 \\
(37.2)\end{array}$ \\
\hline $\begin{array}{l}\text { Note: NPDUIS }=\mathrm{N} \\
{ }^{*} \text { All prescriptions } \mathrm{m} \\
\text { †Provinces in whicl } \\
\text { Ontario and Prince }\end{array}$ & $\begin{array}{l}\text { Prescription Druc } \\
\text { he Beers Criteri } \\
\text { tit } 85 \% \text { of the po } \\
\text { Island. }\end{array}$ & $n$ aru & a & n. ${ }^{1}$ & 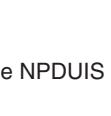 & 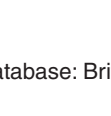 & 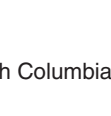 & 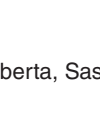 & . & \\
\hline
\end{tabular}

older adults filled at least 1 potentially inappropriate prescription. The proportion ranged from 29.2\% in Prince Edward Island to $40.7 \%$ in Alberta.

A higher proportion of women (42.2\%) than men (31.0\%) filled potentially inappropriate prescriptions in the high-datacoverage provinces. The prevalence of such prescriptions increased with increasing age for women and men in all provinces. In the high-data-coverage provinces, the prevalence was highest among women aged 85 or more (47.0\%).

The province-specific estimates of the cost of potentially inappropriate prescriptions per public drug plan enrollee are given in Table 2. The cost was highest in the 3 provinces with limited data coverage. In the high-data-coverage provinces, the average cost was $\$ 75$ (range $\$ 49$ in Prince Edward Island to $\$ 88$ in Manitoba). Like the patterns of prevalence of prescribing, the average cost of potentially inappropriate prescriptions was higher among women than among men and increased with increasing age. The average cost was highest among women aged 85 or more (\$104).

Table 3 shows the frequency of prescribing and cost of the 20 most frequently used drugs on the Beers list. Although there were differences in the most frequently used medications across provinces (data not shown), the overall totals reflected the pattern in most provinces with high data coverage. Benzodiazepines and other hypnotics were the leading contributors to both frequency and cost of potentially inappropriate prescriptions. These drugs, as well as some whose use is more prevalent among women (such as nitrofurantoin and estrogens), also accounted for most of the sex differences in frequency of prescribing and cost of potentially inappropriate medications.

Extrapolating the results for the high-data-coverage provinces to the entire population of Canadians aged 65 or more (including residents of Quebec and the territories), we estimated the total cost of potentially inappropriate prescriptions in Canada to be $\$ 259$ million for women and $\$ 160$ million for men, for a total of $\$ 419$ million (Table 4).

\section{Interpretation}

We found that filling prescriptions that are potentially inappropriate was relatively common in 2013 among public drug plan enrollees aged 65 years or more from the 9 provinces participating in the NPDUIS database. For the 6 provinces with relatively complete data coverage (British Columbia, Alberta, Saskatchewan, Manitoba, Ontario and Prince Edward Island), 37\% of older people filled at least 1 such prescription. We also found that a higher proportion of women than men filled potentially inappropriate prescriptions, at greater total cost, and that the frequency of 


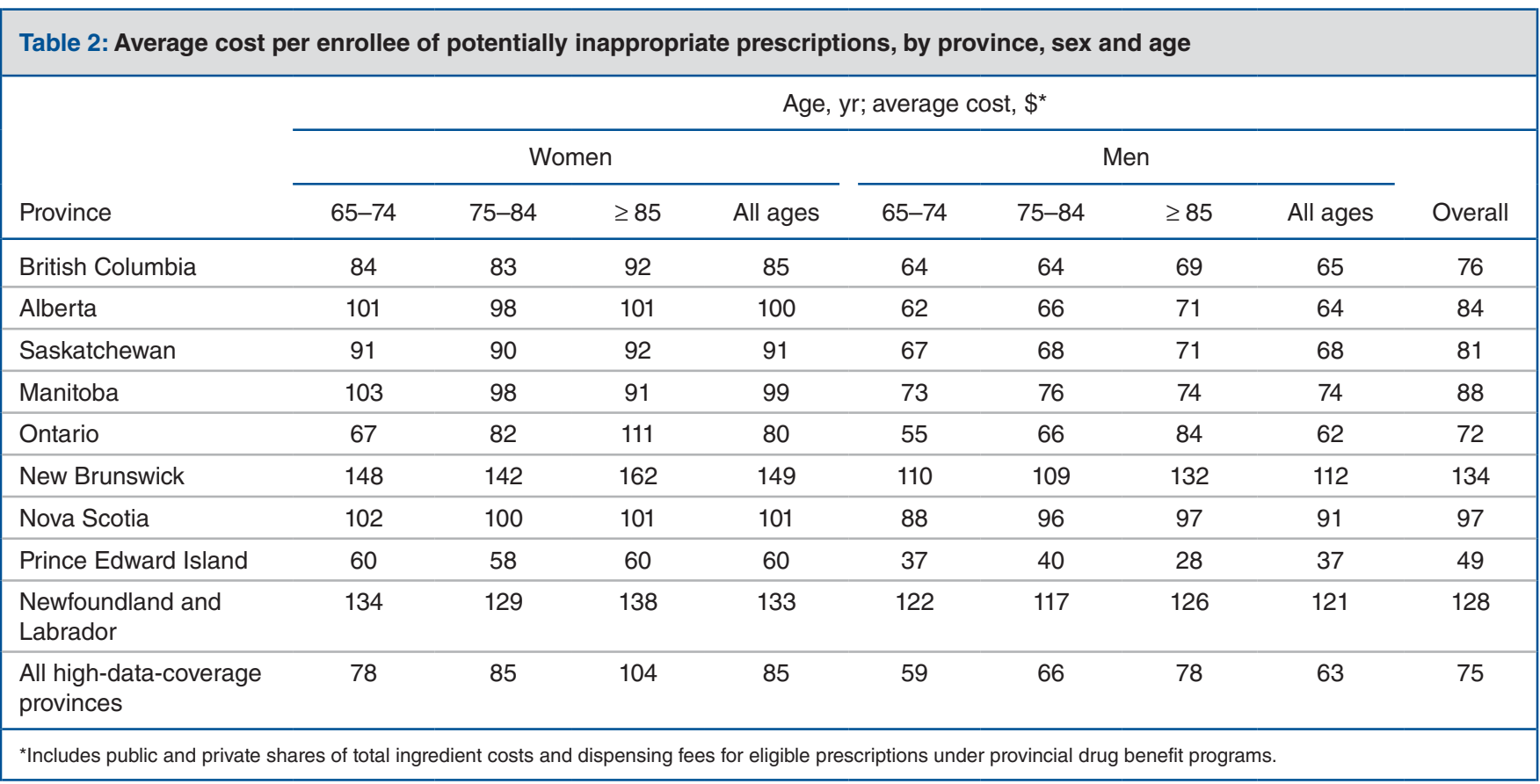

\begin{tabular}{|c|c|c|c|c|c|c|}
\hline \multirow[b]{2}{*}{ Drug } & \multicolumn{3}{|c|}{$\begin{array}{c}\% \text { of enrollees who filled } \geq 1 \\
\text { potentially inappropriate } \\
\text { prescription }\end{array}$} & \multicolumn{3}{|c|}{$\begin{array}{c}\text { Estimated average per-capita cost of } \\
\text { potentially inappropriate } \\
\text { prescriptions, } \$\end{array}$} \\
\hline & Women & Men & Overall & Women & Men & Overall \\
\hline Lorazepam & 11.0 & 6.1 & 8.8 & 6.95 & 3.46 & 5.40 \\
\hline Nitrofurantoin & 8.3 & 1.9 & 5.5 & 3.23 & 0.75 & 2.13 \\
\hline Amitriptyline & 3.9 & 2.0 & 3.1 & 4.12 & 1.85 & 3.11 \\
\hline Quetiapine & 2.8 & 2.2 & 2.5 & 8.24 & 5.95 & 7.22 \\
\hline Clonazepam & 3.0 & 1.9 & 2.5 & 3.02 & 1.82 & 2.49 \\
\hline Zopiclone & 2.9 & 1.9 & 2.4 & 5.25 & 3.50 & 4.47 \\
\hline $\begin{array}{l}\text { Conjugated } \\
\text { estrogens }\end{array}$ & 4.2 & 0.0 & 2.4 & 3.71 & - & 2.06 \\
\hline Glibenclamide & 1.7 & 2.7 & 2.2 & 1.80 & 2.52 & 2.12 \\
\hline Indomethacin & 0.7 & 2.6 & 1.6 & 0.30 & 1.09 & 0.65 \\
\hline Terazosin & 0.4 & 2.9 & 1.5 & 0.82 & 5.04 & 2.70 \\
\hline Oxazepam & 1.8 & 1.1 & 1.5 & 1.61 & 0.84 & 1.27 \\
\hline Risperidone & 1.6 & 1.1 & 1.4 & 5.48 & 3.64 & 4.66 \\
\hline Estradiol & 2.6 & 0.0 & 1.4 & 5.95 & - & 3.31 \\
\hline Temazepam & 1.6 & 1.2 & 1.4 & 1.41 & 0.96 & 1.21 \\
\hline Metoclopramide & 1.3 & 1.0 & 1.2 & 0.65 & 0.45 & 0.56 \\
\hline Amiodarone & 0.7 & 1.1 & 0.9 & 1.41 & 2.26 & 1.79 \\
\hline Meloxicam & 1.1 & 0.6 & 0.9 & 1.65 & 0.93 & 1.33 \\
\hline Cyclobenzaprine & 1.0 & 0.9 & 0.9 & 0.54 & 0.40 & 0.48 \\
\hline $\begin{array}{l}\text { Diclofenac, } \\
\text { combinations }\end{array}$ & 0.8 & 0.8 & 0.8 & 3.98 & 3.59 & 3.80 \\
\hline Alprazolam & 1.1 & 0.6 & 0.8 & 0.96 & 0.49 & 0.75 \\
\hline
\end{tabular}




\begin{tabular}{|lccc|}
\hline \multicolumn{4}{|l|}{$\begin{array}{l}\text { Table 4: Estimated total cost of potentially inappropriate } \\
\text { prescriptions filled by older Canadians in 2013 }\end{array}$} \\
\hline Variable & Women & Men & Overall \\
\hline $\begin{array}{l}\text { Estimated average } \\
\text { cost per enrollee, \$ }\end{array}$ & 84.60 & 63.40 & 75.00 \\
\hline $\begin{array}{l}\text { National population } \\
\text { of age/sex group }\end{array}$ & 3064000 & 2521000 & 5585000 \\
\hline $\begin{array}{l}\text { Estimated total cost, } \\
\text { \$ millions }\end{array}$ & 259 & 160 & 419 \\
\hline
\end{tabular}

prescribing and cost of potentially inappropriate medications increased with increasing age. Finally, we estimate that $\$ 75$ per older Canadian, or $\$ 419$ million in total, was spent on potentially inappropriate prescriptions outside of hospital settings in 2013.

Our estimates concerning the frequency of and sex differences in prescribing of potentially inappropriate medications are consistent with other Canadian estimates and those from other countries. ${ }^{5,6,14}$ Our cost estimates are lower than a population-based estimate from Ireland: using a different criterion for identifying potentially inappropriate prescriptions, Cahir and colleagues ${ }^{16}$ found potentially inappropriate medications cost about Can $\$ 160$ per person aged 70 years or more in 2009-2010. The differences in cost estimates likely stem from a variety of factors, indulging differences in the methods used. The Irish study focused on a slightly older population than ours and used a criterion - the Screening Tool of Older People's Potentially Inappropriate Prescriptions (STOPP) criterion - that included analyses of diagnostic information to identify cases of potentially inappropriate use of otherwise appropriate medications. Because the NPDUIS data are not linked to medical and hospital records, we could not identify diagnosis-specific cases of potentially inappropriate medication prescribing.

Our estimates account only for the direct costs associated with potentially inappropriate prescribing. Fu and colleagues ${ }^{17}$ estimated the incremental health care expenditure attributable to the use of such medications by older Americans in 2001 to be US\$749. With adjustment for exchange rates, inflation and the relative cost of US health care, this is equivalent to a cost of Can\$675 per older Canadian exposed to potentially inappropriate prescriptions in 2013. Combining this estimate with the exposure rates found in our study, we estimate that the indirect health care costs attributable to potentially inappropriate prescribing among older Canadians would be about $\$ 1.4$ billion in 2013. Many of these indirect costs are associated with the adverse effects of inappropriate medications, such as the increased risk of falls, fractures and hospital admissions attributable to older adults' use of benzodiazepines, ${ }^{18}$ which we found to be among the most frequently used Beers list drugs in Canada.

\section{Limitations}

Our study is limited by the availability and quality of data on prescription drug use in Canada. The NPDUIS data set is a
pan-Canadian repository of available public claims data; however, it includes data only for enrollees in public plans and captures only drugs approved for reimbursement under public plans. We therefore estimated national averages using observations from the 6 provinces with reasonably complete data coverage ( $85 \%$ or more) for older populations.

Our results underestimate the frequency and cost of prescribing of potentially inappropriate medications not included in provincial formularies and therefore not approved for coverage or as a contribution toward the deductible of beneficiaries of public plans. The most notable impact of this limitation concerns zopiclone, which is not on the formulary in Saskatchewan or Ontario and is thus not included in the NPDUIS data for those provinces. Market research data indicate that older patients in Saskatchewan and Ontario filled about $\$ 16$ millions' worth of prescriptions for zopiclone in 2012-2013, paid for either out of pocket or through private insurance. ${ }^{12}$ If we assume that the rate of potentially inappropriate prescribing of zopiclone among older patients in Saskatchewan and Ontario was comparable to the rate in British Columbia - a conservative comparator because British Columbia restricts zopiclone coverage $2.2 \%$ of older people in Saskatchewan and Ontario would have been exposed to such potentially inappropriate prescriptions, at a total cost of about $\$ 8$ million.

The NPDUIS data are not linked to the medical and hospital records commonly used to infer health status in analyses of administrative health care data. We therefore could not implement the subset of the Beers Criteria that is conditional on specific medical conditions. To limit the potential for overestimating exposure to potentially inappropriate prescriptions, we included only drugs that the 2012 Beers Criteria suggest should always be avoided. ${ }^{1}$ The exposure rates measured in this study therefore do not account for diagnosis-specific cases of prescribing of potentially inappropriate medications.

Finally, our measure of potentially inappropriate prescribing is based on prescription dispensations. Although dispensation of prescribed drugs is not equivalent to consumption of the medicines, it is likely that most patients who invest the time and out-of-pocket costs necessary to have prescriptions filled do so with intent to consume the drugs. Moreover, as some prescriptions are written but not filled by patients, this measure is arguably an understatement of the extent of potentially inappropriate prescribing for older Canadians.

\section{Conclusion}

We found evidence of frequent dispensation and considerable cost of potentially inappropriate medications among older men and women across Canada. With more than 1 in 3 older people filling at least 1 prescription meeting the Beers Criteria for drug type, dose and duration, we estimate that the total cost of these medications in 2013 was over \$400 million. Attributable health care costs resulting from inappropriate medication use could be several times greater.

As the causes of inappropriate medicine use are many and complex, the solution to the problem requires action that is multipronged and well-coordinated within and across jurisdic- 
tions. Such a strategy will not come cheaply. NPS MedicineWise, the agency that coordinates Australia's national strategy on quality use of medicines, has an annual budget of about Can $\$ 47$ million; however, it generates direct savings to the public drug plan of Can $\$ 67$ million. ${ }^{19}$ Our findings suggest that if a similar investment in Canada were to generate a $10 \%$ reduction in the prescribing and cost of potentially inappropriate medications among older adults only, the investment would likely be more than offset by health system savings while simultaneously generating major benefits to patient health.

\section{References}

1. American Geriatrics Society Beers Criteria Update Expert Panel. American Geriatrics Society updated Beers Criteria for potentially inappropriate medication use in older adults. 7 Am Geriatr Soc 2012;60:616-31.

2. O'Mahony D, O'Sullivan D, Byrne S, et al. STOPP/START criteria for potentially inappropriate prescribing in older people: version 2. Age Ageing 2015;44:213-8

3. McLeod PJ, Huang AR, Tamblyn RM, et al. Defining inappropriate practices in prescribing for elderly people: a national consensus panel. CMA7 1997; 156:385-91.

4. American Geriatrics Society Beers Criteria Update Expert Panel. American Geriatrics Society 2015 updated Beers Criteria for potentially inappropriate medication use in older adults. 7 Am Geriatr Soc 2015;63:2227-46.

5. Aparasu RR, Mort JR. Inappropriate prescribing for the elderly: Beers Criteriabased review. Ann Pharmacother 2000;34:338-46.

6. Guaraldo L, Cano FG, Damasceno GS, et al. Inappropriate medication use among the elderly: a systematic review of administrative databases. BMC Geriatr 2011;11:79.

7. Hill-Taylor B, Sketris I, Hayden J, et al. Application of the STOPP/START criteria: a systematic review of the prevalence of potentially inappropriate prescribing in older adults, and evidence of clinical, humanistic and economic impact. 7 Clin Pharm Ther 2013;38:360-72.

8. Levinson $W$, Huynh T. Engaging physicians and patients in conversations about unnecessary tests and procedures: Choosing Wisely Canada. CMA7 2014; 186:325-6.

9. Ask. Listen. Talk. Overview 2013-2014. Edmonton: Canadian Patient Safety Institute; 2014.

10. Sketris I, Langille Ingram E, Lummis H. Optimal prescribing and medication use in Canada: challenges and opportunities. Ottawa: Health Council of Canada; 2007.

11. Daw JR, Morgan SG. Stitching the gaps in the Canadian public drug coverage patchwork? A review of provincial pharmacare policy changes from 2000 to 2010 . Health Policy 2012;104:19-26.
12. Morgan SG, Smolina K, Mooney D, et al. The Canadian Rx atlas. 3rd edition. Vancouver: Centre for Health Services and Policy Research; 2013.

13. World Health Organization Collaborating Centre for Drug Statistics Methodology. Anatomical Therapeutic Chemical code classification index with defined daily doses. 2014. Available: www.whocc.no/atcddd/ (accessed 2014 Feb. 4).

14. Drug use among seniors on public drug programs in Canada, 2012. Ottawa: Canadian Institute for Health Information; 2014.

15. Table 051-0001. Estimates of population, by age group and sex for July 1, Canada, provinces and territories. Ottawa: Statistics Canada. Available: www5.statcan. gc.ca/cansim/a26?lang=eng\&id=510001 (accessed 2016 June 1).

16. Cahir C, Fahey T, Teeling M, et al. Potentially inappropriate prescribing and cost outcomes for older people: a national population study. Br 7 Clin Pharmacol 2010;69:543-52.

17. Fu AZ, Jiang JZ, Reeves JH, et al. Potentially inappropriate medication use and healthcare expenditures in the US community-dwelling elderly. Med Care 2007;45:472-6.

18. Tannenbaum C, Diaby V, Singh D, et al. Sedative-hypnotic medicines and falls in community-dwelling older adults: a cost-effectiveness (decision-tree) analysis from a US Medicare perspective. Drugs Aging 2015;32:305-14.

19. Annual report 2015. Surry Hills (Australia): NPS MedicineWise; 2015.

Affiliations: School of Population and Public Health (Morgan), University of British Columbia, Vancouver, BC; Canadian Institute for Health Information (Hunt, Rioux, Proulx), Ottawa, Ont.; BC Cancer Agency (Weymann), Canadian Centre for Applied Research in Cancer Control, Vancouver, BC; Departments of Medicine and Pharmacy (Tannenbaum), Université de Montréal, Montréal, Que.

Contributors: Steven Morgan conceived the study, contributed to study design and data acquisition, analysis and interpretation, and drafted the article. Jordan Hunt, Jocelyn Rioux and Jeffery Proulx contributed to study design, data acquisition, analysis and interpretation, and revising the article for important intellectual content. Deirdre Weymann and Cara Tannenbaum contributed to study design, interpretation of data, and revising the article for important intellectual content. All of the authors gave approval of the final version to be published and agreed to act as guarantors of the work.

Funding: This work was supported in part by the Canadian Institutes of Health Research (grant number MOP 119360). The funding agency had no role in the study or decision to publish. All opinions and conclusions are those of the authors.

Supplemental information: For reviewer comments and the original submission of this manuscript, please see www.cmajopen.ca/content/4/2/ E346/suppl/DC1 